\title{
Rapid plant regeneration, analysis of genetic fidelity, and neoandrographolide content of micropropagated plants of Andrographis alata (Vahl) Nees
}

\author{
Sathish Shekhappa Kadapatti and Hosakatte Niranjana Murthy*
}

\begin{abstract}
Background: Andrographis alata (Vahl) Nees is a medicinal plant which was reported to have the highest concentration of neoandrographolide that has several therapeutic values. Natural populations of Andrographis alata are dwindling due to destruction of natural habitat and over exploitation. Therefore, in vitro propagation of Andrographis alata was undertaken, and successful method is presented here.

Results: Micropropagation of Andrographis alata was realized on MS nutrient medium augmented with BAP $(10 \mu \mathrm{M})$, and multiple shoots were regenerated from nodal explants. Induction of roots was attained from shoots on $1 / 4$ concentration of MS nutrient medium supplemented with IBA $(1 \mu \mathrm{M})$. Randomly amplified polymorphic DNA (RAPD) and inter-simple sequence repeat (ISSR) analysis showed that there is genetic fidelity in the regenerated plants. Reverse phase high performance liquid chromatographic analysis of regenerated plants showed the presence of neoandrographolide, equivalent to that of mother plants.

Conclusions: Successful in vitro regeneration of Andrographis alata is presented here, and it is quite useful for its mass multiplication. The micropropagated plants are useful for restoration of plants in nature and for utilization by the pharmaceutical industry for extraction of neoandrographolide.
\end{abstract}

Keywords: Andrographolide, Andrographis alata, Neoandrographolide, Medicinal plant, Micropropagation

\section{Background}

Andrographis belonging to Acanthaceae comprises of many important species which are used as medicinal plants. Andrographis paniculata is a well-known species which is valued in Ayurveda, Unani, Siddha, and Chinese system of medicine for curing snake bite, fever, common cold, dysentery, malaria, diabetes, and hypertension [1]. Diterpenoids, flavonoids, quinic acids, xanthones, and noriridoids are major phytochemicals extracted from $A$. paniculata [1]. Andrographolide, deoxyandrographolide, neoandrographolide, 14-deoxy-11,12-didehydroandrographolide, and isoandrographolide are the prominent

\footnotetext{
* Correspondence: hnmurthy60@gmail.com

Department of Botany, Karnatak University, Dharwad 580003, India
}

diterpenoids which are responsible for antiangiogenic, antiatherosclerotic, antitumor, antidiabetic, antiinflammatory, antioxidant, immunostimulant, hepatoprotective, neuroprotective, and insecticidal activities [2-4].

Andrographis alata (Vahl) Nees is an herbaceous species found distributed in South India [5] which contains varied flavone glycosides including 5,7,2',6'-oxygenated flavone glycosides and 5,2', '-trihydroxy-7-methylflavone-2'-O-ß-D-glucopyronoside [6-8]. Dalawai et al. [9] reported that $A$. alata contains $33.21 \mathrm{mg} / \mathrm{g} \mathrm{DW}$ of neoandrographolide, and neoandrographolide was proved as a potent antioxidant, antiinflammatory, antimalarial, and hepatoprotective phytochemical $[10,11]$. Recent molecular docking combined molecular dynamics studies have demonstrated that neoandrographolide 
is a promising candidate for SARS-CoV-2 (Covid-19) treatment [12]. Andrographis alata is a rare and endemic species which is distributed in South India, and natural populations are dwindling due to destruction of natural habitat and over exploitation [13]. In view of the above, the current study was undertaken to develop in vitro methodology for propagation of $A$. alata, and successful method is presented here for large scale multiplication of plants.

\section{Methods}

\section{Plant material and initiation of cultures}

Andrographis alata was collected from Nagapuri forest, Hassan district, Karnataka, India, and were maintained in Botanical garden. Identification of plant species was confirmed by Prof. S. R. Yadav, Department of Botany, Shivaji University, Kolhapur, India, and voucher specimen was maintained at Herbarium, Shivaji University, Kolhapur, India. Nodal explants were sterilized by using aqueous mercuric chloride (0.1\%; w/v, Sigma, USA) for $5 \mathrm{~min}$. The explants ( $5 \mathrm{~mm}$ in length) were cultured on MS nutrient medium [14] supplemented with 2.5, 5.0, 7.5, and $10.0 \mu \mathrm{M}$ BAP, KN, 2-iP, and TDZ (HiMedia, India) individually and sucrose $(3 \% ; \mathrm{w} / \mathrm{v})$. The cultures were maintained in culture room wherein temperature, light, and relative humidity were set at $25 \pm 2{ }^{\circ} \mathrm{C}, 16 \mathrm{~h}$ light $\left(50 \mu \mathrm{mol} \mathrm{m}^{-2} \mathrm{~s}^{-1}\right) / 8 \mathrm{~h}$ dark, and $60 \%$ respectively.

\section{Induction of roots from shoots}

Regenerated shoots were individually cultured onto $1 / 2$ and $1 / 4$ strength MS nutrient medium containing $3 \%(\mathrm{w} /$ v) sugar, supplemented with $1.0,2.0,5.0$, and $10 \mu \mathrm{M}$ of IAA, IBA and NAA respectively (HiMedia, India) for induction of roots.

\section{Acclimatization of plants}

Micropropagated plants $(5 \mathrm{~cm}$ in height) were transplanted to pots containing equal concentration of soil and cocopeat, and plants were reared in growth chamber where in temperature, light, and relative humidity were set at $25 \pm 2{ }^{\circ} \mathrm{C}, 16 \mathrm{~h}$ light $\left(50 \mu \mathrm{mol} \mathrm{m}{ }^{-2} \mathrm{~s}^{-1}\right) / 8 \mathrm{~h}$ dark, and $60 \%$ respectively.

\section{Analysis of genetic fidelity of micropropagated plants}

DNA was isolated from in vitro regenerated and mother plants of $A$. alata using fresh leaves as per method of Murray and Thompson [15]. Randomly amplified polymorphic DNA (RAPD) was carried out using OPA-01, OPA-02, OPA-04, OPA-08, OPA-09, OPC-07, OPG-03, and OPG-10 primers. Similarly, inter simple sequence repeat (ISSR) analysis was carried out using UBC-811, UBC-815, UBC-818, UBC-823, UBC-827, and UBC-864 primers (Operon, USA). The polymerase chain reaction was carried out using $20 \mathrm{ng}$ template DNA, Taq buffer
$1.5 \mathrm{mM} \mathrm{MgCl}_{2}$, dNTPs $(1 \mathrm{mM} / \mu \mathrm{l})$, Taq polymerase $(2$ units), and primer (5 $\mathrm{pm})$ in a reaction mixture volume of $20 \mu \mathrm{l}$ in an Eppendorf master cycler for 45 cycles. Amplified DNA products were run on 1.0\% agarose gel prepared in $0.5 \mathrm{x}$ TAE buffer, stained with ethidium bromide, and bands were visualized under UV light. All molecular biology chemicals were obtained from HiMedia Laboratories, Mumbai, India.

\section{Quantitative analysis of neoandrographolide}

Quantitative estimation of neoandrographolide in the leaf and stem methanolic extract of Andrographis alata was carried out as per the protocol of Dalawai et al. [9] and Pholphana et al. [16] with minor modification by using high performance liquid chromatography (Shimadzu prominence unit with degasser DGU-20A 5R, low-pressure quaternary pump LC $20 \mathrm{AD}$ ). Chromatographic separation was carried out using Nova-Pak's reversed phase C18 column $(4 \mathrm{~mm}, 4.6 \mathrm{~mm} \times 250 \mathrm{~mm})$. The mobile phase consisted of $30 \%$ acetonitrile in water and $0.70 \mathrm{ml} / \mathrm{min}$ flow rate. The injection volume was $20 \mu \mathrm{l}$. The temperature of the column was controlled at $25{ }^{\circ} \mathrm{C}$, and samples were detected using PD-M20A photo diode array detector. The neoandrographolide was identified by comparing retention time of samples with reliable standard chromatographic peaks at $205 \mathrm{~nm}$, and neoandrographolide concentration was calculated using absorbance intensity (mAU) against standards. The data are expressed as mean \pm standard deviation (SD, $n=3$ ).

\section{Data analysis}

Randomized block method was followed for establishment of experiments. There were six replicates for each treatment. The pooled data of three repeated experiments is presented in the tables. Analysis of variance treatment was applied to all the data using Duncan's multiple range test.

\section{Results \\ Multiple shoot regeneration}

Nodal explants cultured on MS medium containing several cytokinins produced multiple shoots from axillary meristem (Fig. 1a). Medium without growth regulators have not influenced shoot development from nodal explants (Table 1). Among the four cytokinins (BAP, 2-iP, $\mathrm{KN}$, and TDZ) tested, BAP-supplemented medium induced highest shoot regeneration frequency (83.33\%), number of shoots per explants $(12.20 \pm 0.64)$, and shoot length $(1.68 \pm 0.06 \mathrm{~cm})$ (Table 1$)$. Of the various concentration of BAP tested $(2.5,5.0,7.5$, and $10 \mu \mathrm{M}), 10 \mu \mathrm{M}$ BAP was superior in induction of axillary shoots, and optimum of 12 shoots were regenerated from nodal explants on this medium (Fig. 1b; Table 1). Medium containing 2-iP and $\mathrm{KN}$ induced 1-2 axillary shoots, 

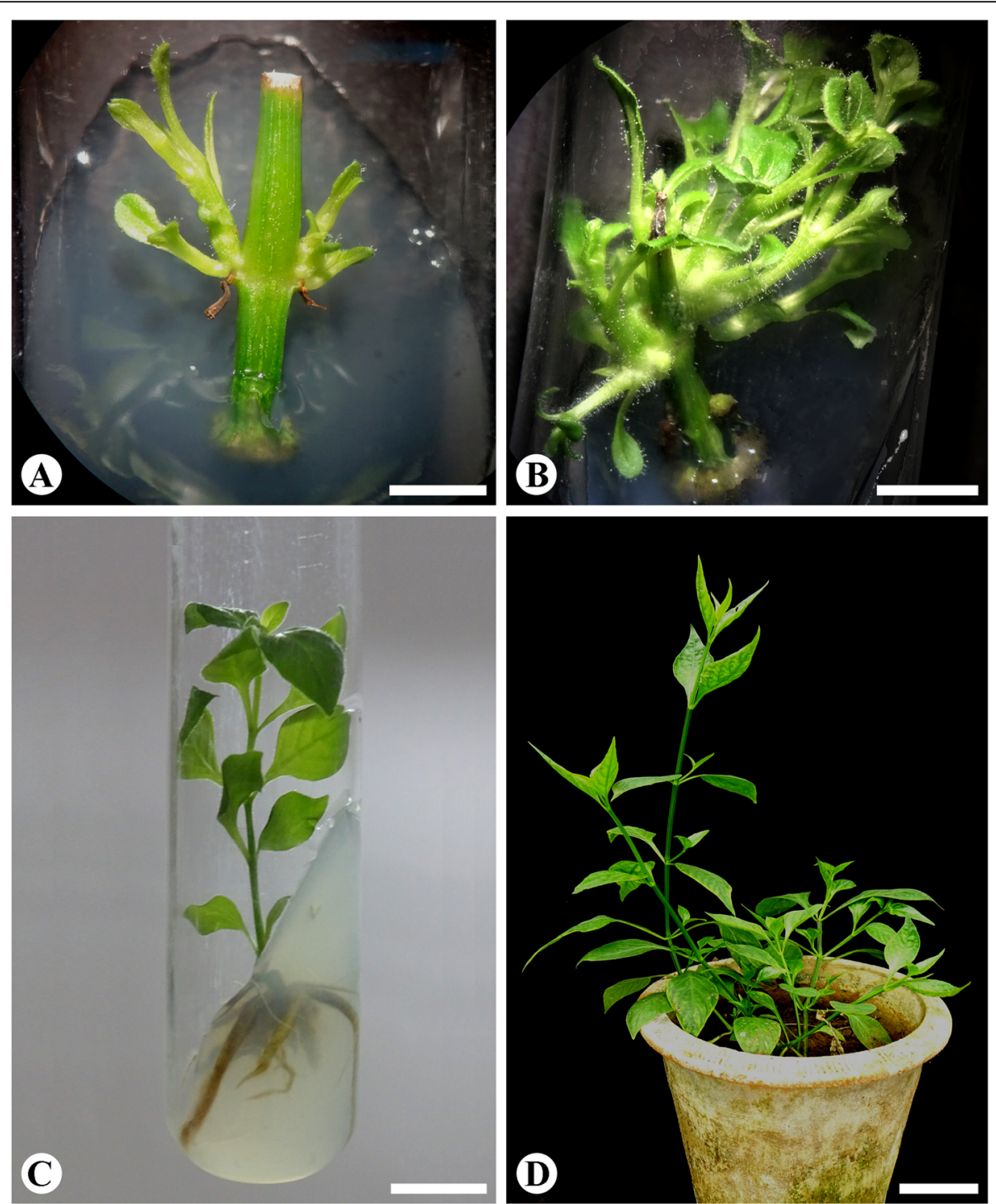

Fig. 1 Multiple-shoot regeneration from the nodal explants Andrographis alata. a Induction of axillary shoot buds on MS nutrient medium supplemented with $10 \mu \mathrm{M}$ BAP after 2 weeks of culture $(\mathrm{bar}=0.25 \mathrm{~cm})$. b Multiple shoots regenerated on MS nutrient medium supplemented with $10 \mu \mathrm{M}$ BAP after 4 weeks of culture $(\mathrm{bar}=0.62 \mathrm{~cm}$ ). c Adventitious root induction from regenerated shoots on $1 / 4$ strength MS nutrient medium supplemented with $1 \mu \mathrm{M}$ IBA after 4 weeks of culture (bar $=1.25 \mathrm{~cm}$ ). $\mathbf{d}$ Four-week-old plants transferred to pots containing soil and cocopeat $(\mathrm{bar}=7.75 \mathrm{~cm})$

whereas medium supplemented with TDZ induced only callus formation from the explants (Table 1). The shoots developed from the nodal explants were excised, and the original explants were transferred to shoot regeneration medium (MS $+10 \mu \mathrm{M}$ BAP) and new shoot developed again from the nodal regions. The explants so transferred continued to produce shoots up to third cycle.

\section{Induction of roots from shoots}

Regenerated shoots of Andrographis alata were cultured on $1 / 2$ and $1 / 4$ strength MS nutrient medium containing 1 , 2,5 , and $10 \mu \mathrm{M} \mathrm{NAA}, \mathrm{IBA}$, and IAA, and the results are presented in Table 2 . There were significant differences in percentage of root induction, number of roots per explant, and root length among the different auxins and concentrations tested (Table 2). Optimum rooting percentage (100\%) and number of roots (19/shoot) were realized when shoots were cultured on $1 / 4$ strength nutrient medium supplemented with $1 \mu \mathrm{M}$ IBA (Fig. 1c). The greatest root length $(3.06 \mathrm{~cm})$ was also observed on the same medium. On MS medium lacking auxins, rooting of shoots was not observed. Medium supplemented with NAA and IAA also induced rooting of shoots; however, percentage of response, number of roots per shoot, and root length were inferior when compared to IBAsupplemented medium (Table 2). Micropropagated 
Table 1 Response of nodal explants of Andrographis alata cultured on MS medium supplemented with cytokinins

\begin{tabular}{|c|c|c|c|c|}
\hline Growth regulator & Concentration $(\mu \mathrm{M})$ & Percentage of regeneration & Mean number of shoots per explants & Average shoot length $(\mathrm{cm})$ \\
\hline Control & 0.0 & 0 & $0 \pm 0^{f}$ & $0 \pm 0^{9}$ \\
\hline \multirow[t]{4}{*}{$\mathrm{KN}$} & 2.5 & 83.33 & $1.2 \pm 0.13^{e}$ & $2.52 \pm 0.17^{a}$ \\
\hline & 5 & 66.66 & $1 \pm 0.00^{\mathrm{e}}$ & $1.95 \pm 0.03^{b}$ \\
\hline & 7.5 & 66.66 & $1.25 \pm 0.13^{\mathrm{e}}$ & $1.57 \pm 0.14^{\mathrm{cd}}$ \\
\hline & 10 & 50 & $1 \pm 0^{e}$ & $0.96 \pm 0.09^{e}$ \\
\hline \multirow[t]{4}{*}{$2-i P$} & 2.5 & 83.33 & $1.20 \pm 0.13^{\mathrm{e}}$ & $0.53 \pm 0.02^{f}$ \\
\hline & 5 & 83.33 & $1.25 \pm 0.16^{\mathrm{e}}$ & $0.46 \pm 0.05^{f}$ \\
\hline & 7.5 & 66.66 & $1.50 \pm 0.18^{\mathrm{e}}$ & $0.58 \pm 0.05^{f}$ \\
\hline & 10 & 66.66 & $1 \pm 0.00^{\mathrm{e}}$ & $0.60 \pm 0.04^{f}$ \\
\hline \multirow[t]{4}{*}{ BAP } & 2.5 & 83.33 & $2.4 \pm 0.16^{d}$ & $0.87 \pm 0.04^{e}$ \\
\hline & 5 & 83.33 & $5.25 \pm 0.31^{c}$ & $0.93 \pm 0.08^{\mathrm{e}}$ \\
\hline & 7.5 & 75.00 & $8.6 \pm 0.26^{b}$ & $1.37 \pm 0.07^{d}$ \\
\hline & 10 & 83.33 & $12.20 \pm 0.64^{\mathrm{a}}$ & $1.68 \pm 0.06^{c}$ \\
\hline \multirow[t]{4}{*}{ TDZ } & 2.5 & 50 & $0 \pm 0^{f}$ & $0 \pm 0^{9}$ \\
\hline & 5 & 66.66 & $0 \pm 0^{f}$ & $0 \pm 0^{9}$ \\
\hline & 7.5 & 66.66 & $0 \pm 0^{f}$ & $0 \pm 0^{g}$ \\
\hline & 10 & 66.66 & $0 \pm 0^{f}$ & $0 \pm 0^{g}$ \\
\hline
\end{tabular}

Data was recorded after 4 weeks of culture. Each value represents the mean \pm standard error. Treatment mean values followed by different letters in their superscript are significantly different from each other $(p=0.05)$ according to Duncan's multiple range test

Table 2 Effect of auxins supplemented MS medium on induction of roots from the shoots of Andrographis alata

\begin{tabular}{|c|c|c|c|c|}
\hline Growth regulator & Concentration $(\mu \mathrm{M})$ & Percentage of response & Mean number of roots per shoot & Average root length $(\mathrm{cm})$ \\
\hline \multicolumn{5}{|c|}{ MS half strength medium + auxins } \\
\hline Control & 0 & 0 & $0 \pm 0^{e}$ & $0 \pm 0^{\mathrm{e}}$ \\
\hline \multirow[t]{4}{*}{ NAA } & 1 & 0 & $0 \pm 0^{e}$ & $0 \pm 0^{\mathrm{e}}$ \\
\hline & 2 & 0 & $0 \pm 0^{\mathrm{e}}$ & $0 \pm 0^{\mathrm{e}}$ \\
\hline & 5 & 0 & $0 \pm 0^{e}$ & $0 \pm 0^{\mathrm{e}}$ \\
\hline & 10 & 0 & $0 \pm 0^{\mathrm{e}}$ & $0 \pm 0^{\mathrm{e}}$ \\
\hline \multirow[t]{4}{*}{ IBA } & 1 & 100 & $1.4 \pm 0.16^{c}$ & $2.10 \pm 0.07^{b}$ \\
\hline & 2 & 100 & $5.6 \pm 0.16^{\mathrm{b}}$ & $1.48 \pm 0.03^{c}$ \\
\hline & 5 & 100 & $12.20 \pm 1.0^{\mathrm{a}}$ & $2.18 \pm 0.07^{b}$ \\
\hline & 10 & 16.66 & $1 \pm 0.66^{\mathrm{cd}}$ & $0.30 \pm 0.04^{d}$ \\
\hline \multirow[t]{4}{*}{ IAA } & 1 & 100 & $2 \pm 0^{c}$ & $2.19 \pm 0.07^{b}$ \\
\hline & 2 & 100 & $2 \pm 0.21^{c}$ & $2.80 \pm 0.09^{\mathrm{a}}$ \\
\hline & 5 & 0 & $0 \pm 0^{e}$ & $0 \pm 0^{\mathrm{e}}$ \\
\hline & 10 & 0 & $0 \pm 0^{e}$ & $0 \pm 0^{e}$ \\
\hline \multicolumn{5}{|c|}{ MS quarter strength medium + auxins } \\
\hline Control & 0.00 & 0 & $0 \pm 0^{9}$ & $0 \pm 0^{h}$ \\
\hline \multirow[t]{4}{*}{ NAA } & 1 & 100 & $4 \pm 0.21^{\mathrm{ef}}$ & $2.34 \pm 0.04^{c}$ \\
\hline & 2 & 100 & $11.80 \pm 0.64^{\mathrm{b}}$ & $2.42 \pm 0.10^{c}$ \\
\hline & 5 & 66.66 & $11.50 \pm 0.42^{b}$ & $1.25 \pm 0.10^{g}$ \\
\hline & 10 & 66.66 & $12.33 \pm 0.42^{b}$ & $1.30 \pm 0.16^{\mathrm{fg}}$ \\
\hline \multirow[t]{4}{*}{ IBA } & 1 & 100 & $19.0 \pm 1.65^{\mathrm{a}}$ & $3.06 \pm 0.07^{\mathrm{ab}}$ \\
\hline & 2 & 100 & $11.60 \pm 0.54^{b}$ & $2.96 \pm 0.10^{b}$ \\
\hline & 5 & 100 & $4.80 \pm 0.13 \mathrm{~d}^{\mathrm{e}}$ & $3.36 \pm 0.11^{\mathrm{a}}$ \\
\hline & 10 & 100 & $8.0 \pm 0.63^{c}$ & $2.80 \pm 0.13^{b}$ \\
\hline \multirow[t]{4}{*}{ IAA } & 1 & 66.66 & $4.25 \pm 0.16 \mathrm{de}$ & $1.85 \pm 0.10^{\mathrm{de}}$ \\
\hline & 2 & 100 & $6.20 \pm \pm 0.48^{c d}$ & $2.10 \pm 0.07^{c d}$ \\
\hline & 5 & 100 & $11.40 \pm 0.80^{\mathrm{b}}$ & $1.20 \pm 0.20^{9}$ \\
\hline & 10 & 66.66 & $2.0 \pm 0^{f}$ & $1.62 \pm 0.13^{\text {ef }}$ \\
\hline
\end{tabular}




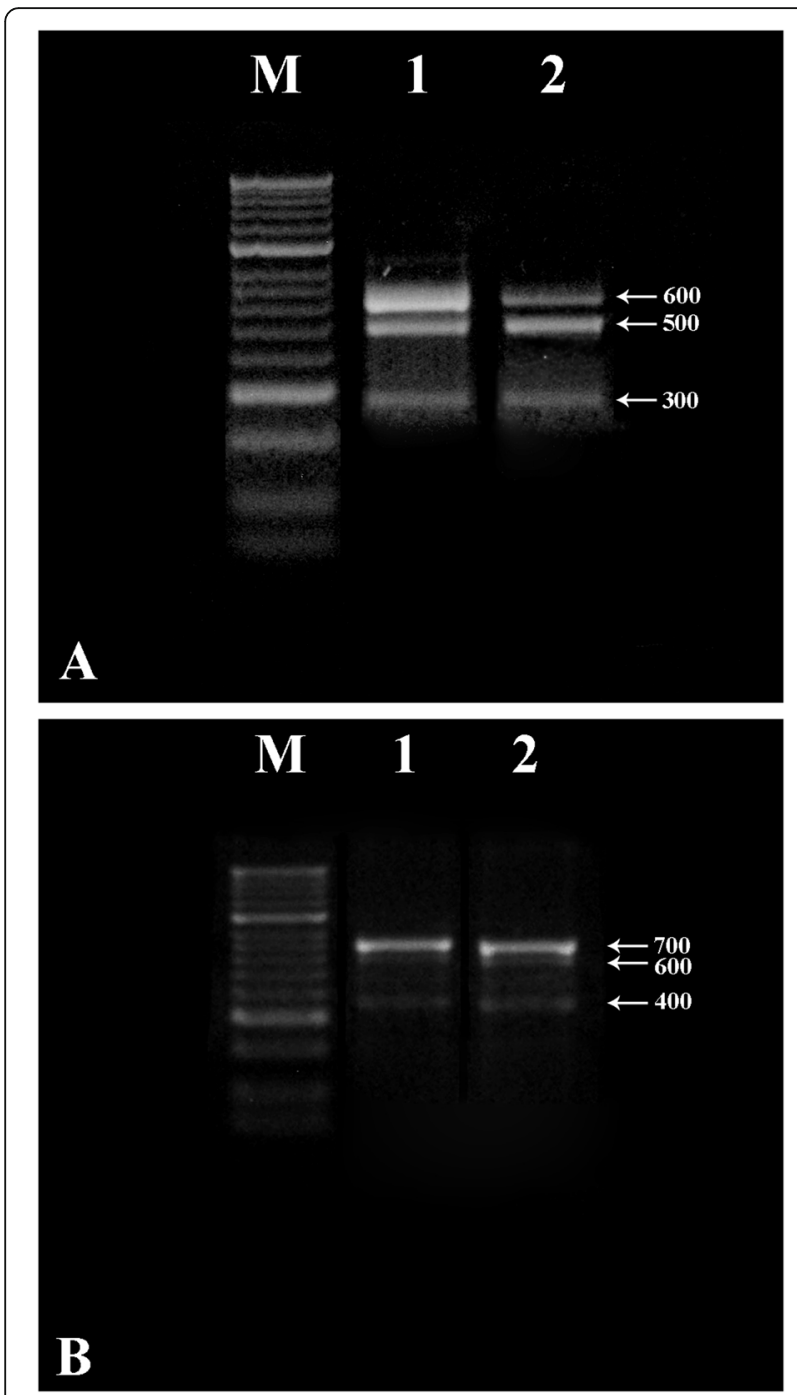

Fig. 2 a RAPD profile of in vitro regenerated and mother plants of A. alata obtained with primer OPG-03. b ISSR profile of in vitro regenerated and mother plants of $A$. alata obtained from primer UBC-818 [lane M-DNA maker (1 kbp ladder); lane 1-in vitro regenerated plant; lane 2 -mother plant of $A$. alata used as explants)

plants were successfully transferred to pots containing mixture of soil and cocopeat in equal concentrations (Fig. 1d).

\section{Genetic fidelity of regenerated plants}

Genetic fidelity of in vitro regenerated $A$. alata was tested using RAPD and ISSR primers, and results obtained from two best RAPD (OPG-03) and ISSR (UBC818) primers are presented in Fig. 2. Both the primers produced three monomorphic bands in mother plant as well as in vitro regenerated plants, which depict genetic fidelity of regenerated plants.

\section{Quantitative analysis of neoandrographolide}

Amount of neoandrographolide was determined in parent and in vitro regenerated plants through RP-HPLC method. RP-HPLC chromatograms are presented in Fig. 3. Figure 3a represents peak areas of andrographolide (AG), neoandrographolide (NAG), and 14-deoxy-11,12-didehydroandrographolide (DDAG) standards. Figure $3 \mathrm{~b}$ and $\mathrm{c}$ depict the chromatograms of mother and in vitro regenerated plants respectively. Only neoandrographolide was detected in the mother and regenerated plants. Based on peak area measurements, the amount of neoandrographolide of mother and regenerated plants was found to be $32.32 \mathrm{mg} / \mathrm{g} \mathrm{DW}$.

\section{Discussion}

The current study reveals that cytokinin-supplemented medium is appropriate for shoot regeneration from the nodal explants of Andrographis alata (Table 1). Among the varied cytokinins applied to the MS medium, BAPcontaining medium was found suitable for regeneration of multiple shoots from nodal explants (Table 1). Multiple shoot regeneration from nodal explants on cytokinin medium was also reported in other medicinal plants such as Artemisia nilagirica var. nilagirica [17], Artemisia japonica [18], Feronia limonia [19], Spilanthes oleracea [20], and Vitex trifolia [21]. Among various cytokinins used, BAP was found excellent for axillary shoot induction (Table 1), and again of the several concentrations BAP tested, $10 \mu \mathrm{M}$ BAP was superior in optimum axillary shoot induction (Table 1). These results are in congruent with earlier reports of BAP being used as a potent cytokinin for induction of multiple shoots in $\mathrm{Ar}$ temisia vulgaris and Puya berteroniana [22-24]. Further, shoot regeneration frequency depends on type and concentration of cytokinin used (Table 1), such reports are already on record including Andrographis paniculata [25, 26], Nothapodytes nimmoniana [27], and Enicostema axillare [28].

Rooting of in vitro regenerated shoots is crucial for acclimatization of plants. Salt strength of medium and growth regulators supplemented to the medium is important factors which control the rooting of shoots. Auxins play a pivotal role in induction of adventitious root from in vitro regenerated shoots. Optimum root induction was realised on IBA-supplemented medium (1 $\mathrm{MM}$; Fig. 1c; Table 2). Similar results were recorded in Andrographis paniculata [25], Artemisia nilagirica var. nilagirica [17], and Artemisia japonica [18] wherein IBA was best for induction of roots from regenerated shoots. It was reported that higher salt strength of medium inhibits rooting of in vitro regenerated shoots and invariably roots develop callus along with roots [17]. In the current study, optimal percentage of rooting, number of roots, and root length were recorded on the medium supplemented with $1 / 4$ strength MS nutrient medium 

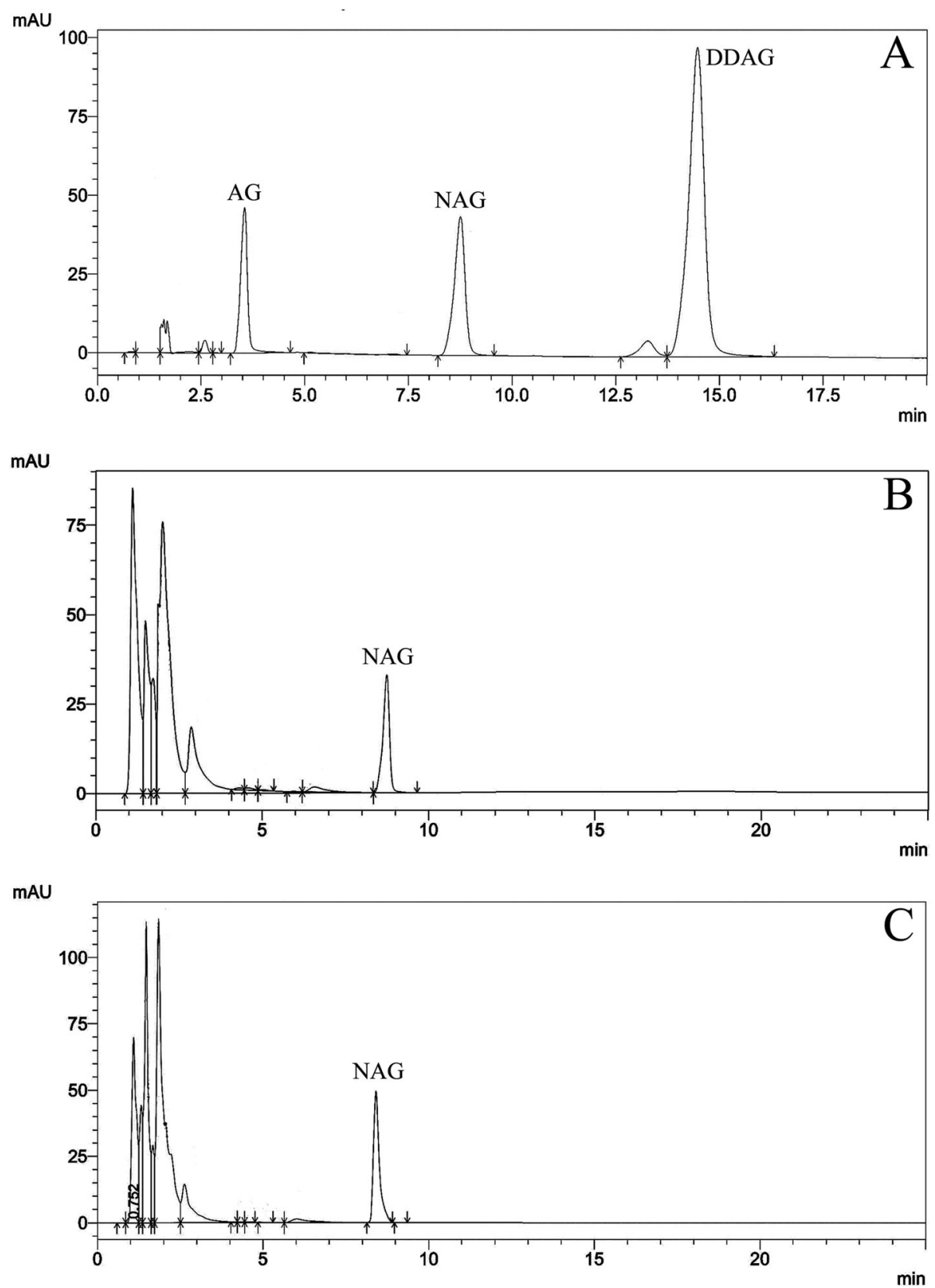

Fig. 3 RP-HPLC elution profile of neoandrographolide (standard, panel a). RP-HPLC elution profile of neoandrographolide isolated from mother plant (panel b). RP-HPLC elution profile of neoandrographolide isolated from in vitro regenerated plants (panel $\mathbf{c}$ )

with IBA $(1 \mu \mathrm{M}$; Table 2). Similarly, reduced salt concentration of the culture medium was reported to be beneficial for root regeneration from shoots of Feronia limonia [21] and Cattleya [29].

Plant regenerated from axillary and apical buds are reported to possess genetic fidelity, whereas callusmediated regeneration may depict tendency for genetic variation [30]. In the present study, genetic fidelity of regenerated plants was assessed using molecular markers. RAPD and ISSR analysis results demonstrated the development of monomorphic bands with the mother and in vitro regenerated plants which depicts genetic fidelity (Fig. 2). Such strategy adopting molecular technique for assessing genetic fidelity has been well documented in the literature $[17,20,26]$.

Shoot cultures have been efficiently used for the production of secondary metabolites in vitro, for example, production of asiaticoside and madecassoside was demonstrated in shoot cultures of Centella asiatica [31]. Hypericins were produced from regenerated shoots of 
hairy St John's-wort and spotted St. John's-wort by Coste et al. [32]. In the current study, we have quantified the neoandrographolide in the regenerated plants, and results showed that the amount of neoandrographolide in in vitro regenerated plants was similar to mother plants (32.21 mg/g DW; Fig. 3).

\section{Conclusion}

A simple, useful in vitro regeneration protocol was presented here for Andrographis alata. Highest frequency of shoots (12 shoots/explant) was regenerated on MS nutrient medium containing $10 \mu \mathrm{M}$ BAP. Root regeneration from shoots was attained on $1 / 4$ strength MS medium containing $1 \mu \mathrm{M}$ IBA. Molecular analysis showed the genetic fidelity of regenerated plants. Further, RP-HPLC analysis demonstrated that regenerated plants possessed optimum concentration of neoandrographolide. These results suggest that micropropagated plants of Andrographis alata are useful for both extraction of neoandrographolide for pharmaceutical use as well as for restoration of plants in nature.

\begin{abstract}
Abbreviations
BAP: 6-Benzyl amino purine; DW: Dry weight; IAA: Indole acetic acid; IBA: Indole-butyric acid; KN: Kinetin; 2-iP: 2-Isopentyl adenine; MS: Murashige and Skoog medium; NAA: 1-Napthlene acetic acid; RP-HPLC: Reverse phase high performance liquid chromatography; SARS-CoV-2: Severe acute respiratory syndrome corona virus 2; TDZ: Thidiazuron
\end{abstract}

\section{Acknowledgements}

This work was supported UGC-BSR mid-career award grant [No. F.19-223/ 2018/ (BSR)].

\section{Authors' contributions}

HNM planned and designed the experiments; SSK conducted the experiments. Both the authors together written and approved the manuscript.

\section{Funding}

No specific funding was received for this paper.

\section{Availability of data and materials}

Not applicable

\section{Ethics approval and consent to participate}

Not applicable.

\section{Consent for publication}

Not applicable.

\section{Competing interests}

Authors declare that they have no conflict of interest.

Received: 22 October 2020 Accepted: 20 January 2021

Published online: 26 January 2021

\section{References}

1. Hossain MS, Urbi Z, Sule A, Hafizur Rahman KM (2014) Andrographis paniculata (Burm. f.) Wall. ex Nees: A review of ethnobotany, phytochemistry, and pharmacology. Sci World J. Article ID 274905. https://doi.org/10.1155/2014/274905
2. Dai Y, Chen SR, Chai L, Zhao J, Wang Y, Wang Y (2019) Overview of pharmacological activities of Andrographis paniculata and its major compound andrographolide. Crit Rev Food Sci Nutr 59(S1):S17-S29

3. Lim JCW, Chan TK, Ng DSW, Sagineedu SR, Stansias J, Wong WSF (2012) Andrographolide and its analogues: versatile bioactive molecules for combating inflammation and cancer. Clin Exp Pharmacol Physiol 39:300310

4. Lu J, Ma Y, Wu J, Huang H, Wang H, Wang X, Chen Z, Chen J, He H, Huang C (2019) A review for the neuroprotective effects of andrographolide in the central nervous system. Biomed Pharmacother 117:109078

5. Gamble JS (1956) Flora of the presidency of Madras. Botanical Survey of India. Calcutta 2:1049

6. Damu AG, Jayaprakasam B, Gunasekar D (1998) A new flavone 2'-glucoside from Andrographis alata. J Asian Nat Prod Res 1:133-138

7. Damu AG, Jayaprakasam B, Rao KV, Gunasekar D. A flavones glycoside from Andrographis alata. Phytochemistry 49:1811-1813

8. Das B, Ramu R, Rao YK, Reddy MR, Harish H, Reddy VS, Ramakrishna KVS (2006) Acylated 5,7, 2',6'-oxygenated flavone glycosides from Andrographis alata. Phytochemistry 67:978-983

9. Dalawai D, Aware C, Jadhav JP, Murthy HN (2019) RP-HPLC analysis of diterpene lactones in leaves and stem of different species of Andrographis. NatProd Res. 1-4. https://doi.org/10.1080/14786419.2019.1662004

10. Kapil A, Koul IB, Banerjee SK, Gupta BD (1993) Antihepatotoxic effects of major diterpenoid constituents of Andrographis paniculata. Biochem Pharmacol 46:182-185

11. Batkhuu JK, Hattori K, Takano F, Fushiya S, Oshiman K, Fjujimiya Y (2002) Suppression of NO production in activated macrophages in vitro and ex vivo by neoandrographolide from Andrographis paniculata. Biol Pharm Bull 25:1174-1174

12. Murugan NA, Pandian CJ, Jeyakanthan J (2020) Computational investigation on Andrographis paniculata phytochemicals to evaluate their potency against SARS-CoV-2 in comparision to known antiviral compounds in drug trails. J Biomol Struct Dyn. https://doi.org/10.1080/07391102.1777901

13. Neeraja C, Hari Krishna P, Sudhakar Reddy C, Giri CC, Rao KV, Reddy VD (2015) Distribution of Androgrpahis species in different districts of AndhraPradesh. Proc. Natl. Acad. Sci. India, Sect B Biol Sci 85:601-606

14. Murashige T, Skoog F (1962) A revised medium for rapid growth and bioassays with tobacco tissue cultures. Physiol Plant 15:473-497

15. Murray MG, Thompson WF (1980) Rapid isolation of high molecular weight plant DNA. Nucl Acids Res 8:4321-4325

16. Pholphana N, Rangkadilok N, Thongnest S, Ruchirawat S, Ruchirawat M, Satayavivad J (2004) Determination and variation of three active diterpenoids in Andrographis paniculata (Burm. f.) Nees. Phytochem Anal 15:365-371

17. Shinde S, Joseph KS, Jain JR, Manohar SH, Murthy HN. Efficient in vitro propagation of Artemisia nilagirica var. nilagirica (Indian wormwood) and assessment of genetic fidelity of micropropagated plants. Physiol Mol Biol Plants 22:595-603

18. Shinde S, Katewal PR, Shanbhag DD, Joseph KS, Murthy HN (2017) In vitro propagation of Artemisia japonica. J Herbs Spices Med Plants 23:36-43

19. Hiregoudar LV, Ashok Kumar HG, Murthy HN (2005) In vitro culture of Feronia limonia (L.) Swingle from hypocotyl and intermodal explants. Biol Plant 49:41-45

20. Dandin VS, Naik PM, Murthy HN, Park SY, Lee EJ, Paek KY (2014) Rapid regeneration and analysis of genetic fidelity and scopoletin contents of micropropagated plants of Spilanthes oleracea. L J Hortic Sci Biotech 89:7985

21. Hiregoudar LV, Murthy HN, Bhat JG, Nayeem A, Hema BP, Hahn EJ, Paek KY (2006) Rapid clonal propagation of Vitex trifolia. Biol Plant 50:291-294

22. Fulzele DP, Sipahimaalani AT, Heble MR (1991) Tissue culture of Artemisia annua: organogenesis and artemisinin production. Phytother Res 5:149-153

23. Sujatha G, Ranjitha Kumari BD (2007) Effect of phytohormones on micropropagation of Artemisia vulgaris L. Acta Physiol Plant 29:189-195

24. Viehmannova I, Cepkova PH, Vitamvas J, Streblova P, Kisilova J (2016) Micropropagation of a giant ornamental bromeliad Puya berteroniana though adventitious shoots and assessment of their genetic stability through ISSR primers and flow cytometry. Plant Cell Tissue Organ Cult 125:293-302

25. Purkayastha J, Sugla T, Paul A, Solleti S, Sahoo L (2008) Rapid in vitro multiplication and plant regeneration from nodal explants of Andrographis 
paniculata: a valuable medicinal plant. In Vitro Cell Dev Biol Plant 44:442-

447

26. Dandin VS, Murthy HN (2012) Regeneration of Andrographis paniculata Nees: Analysis of genetic fidelity and andrographolide content in micropropagated plants. Afr J Biotechnol 11:12464-12471

27. Dandin VS, Murthy HN (2012) Enhanced in vitro multiplication of Nothapodytes nimmoniana Graham using semisolid and liquid cultures and estimation of camptothecin in the regenerated plants. Acta Physiol Plant 24: 1381-1386

28. Sasidharan P, Jayachitra A (2017) Direct shoot bud regeneration from shoot tip explants of Enicostema axillare: an important medicinal plant. AgroforSyst 91:471-477

29. Dewir YH, El-Mahrouk ME, Murthy HN, Paek KY (2015) Micropropagation of Cattleya: Improved in vitro rooting and acclimatization. Hort Environ Biotechnol 56:89-93

30. Rani V, Raina SN (2000) Genetic fidelity of organized meristem derived micropropagated plants: A critical reappraisal. In Vitro Cell Dev Biol Plant 36 319-330

31. Aziz ZA, Davey MR, Power JB, Anthony P, Smith RM, Lowe KC (2007) Production of asiaticoside and madecassoside in Centella asiatica in vitro and in vivo. Biologia Plant 51:34-42

32. Coste A, VIse L, Halmagyi A, Deliu C, Coldea G (2011) Effects of growth regulators and elicitors on production of secondary metabolites in shoot cultures of Hypericum hirsutum and Hypericum maculatum. Plant Cell Tiss. Organ Cult 106:279-288

\section{Publisher's Note}

Springer Nature remains neutral with regard to jurisdictional claims in published maps and institutional affiliations.

\section{Submit your manuscript to a SpringerOpen ${ }^{\circ}$ journal and benefit from:}

- Convenient online submission

- Rigorous peer review

- Open access: articles freely available online

High visibility within the field

- Retaining the copyright to your article

Submit your next manuscript at $\boldsymbol{\nabla}$ springeropen.com 